\title{
Changes in eating disorder characteristics over the years
}

\author{
Michel Probst $^{1,2}$ (D) | Kärt Kürsa ${ }^{1} \mid$ Tine Van Damme $^{1} \mid$ Jolien Diedens $^{2} \mid$ Johan Vanderlinden ${ }^{2}$
}

${ }^{1}$ Department of Rehabilitation Sciences, KU Leuven, Belgium

${ }^{2}$ Eating Disorder Unit, UPC-KU Leuven, Belgium

\section{Correspondence}

Michel Probst, Department of Rehabilitation Sciences, KU Leuven, Herestraat 49 bus 1510, 3000 Leuven, Belgium.

Email: michel.probst@kuleuven.be

\begin{abstract}
Since 1980, the diagnostic criteria of patients with eating disorders (ED) have changed over the years. Are these changes also expressed in the clinical features of the ED patients? A cross-sectional sample was drawn consisting of 100 consecutive female patients' files diagnosed with anorexia nervosa (AN) and bulimia nervosa (BN) and bulimia nervosa and admitted at an inpatient unit from the first of January 1990, 2000, and 2010, respectively. Several reliable and well-validated questionnaires (Eating Disorder Inventory, Body Attitude Test, Symptom Checklist, and the Beck Depression Inventory) were administered and scores were compared. The ratio AN/BN remained the same (65/35). No differences were found between the three cohorts except for depression, which increased over the years. This pattern is the same for the subsamples of anorexia nervosa and bulimia nervosa. Specific characteristics of eating disorder pathology did not change across time.
\end{abstract}

\section{KEYWORDS}

body image, diagnostic characteristics, eating disorders, inpatient treatment

\section{1 | INTRODUCTION}

Since Bruch (1962) and Russell (1979) described the clinical characteristics of anorexia nervosa (AN) and bulimia nervosa (BN), the diagnostic criteria following the Diagnostic and Statistical Manual of Mental Disorders (DSM) have changed over time.

Eating disorders (EDs) are very multifaceted pathologies being represented by a variety of symptoms and characteristics (Treasure, Claudino, \& Zucker, 2010), which can be measured with the help of international well-accepted standardized questionnaires. On the basis of this information, clinicians can determine the relative severity and the possible presence of the comorbidities. Interestingly, the official specification concerning severity was only made in the most recent edition of DSM (i.e., DSM-V; American Psychiatric Association [APA], 2013). In the fifth edition, severity is determined through body mass index (BMI) and through the frequency of inappropriate compensatory behaviours for $\mathrm{AN}$ and $\mathrm{BN}$, respectively (APA, 2013). As the official severity measure did not exist previously, prior research has defined the severity in numerous ways, that is, based on psychological, behavioural, and physical factors (Bravender, Robertson, Woods, Gordon, \& Forman, 1999; Haynos, Roberto, \& Attia, 2015; Spindler \& Milos, 2007).

Trend studies are not so common in the field of EDs, and only reviews are able to reflect to some extent how ED-related aspects have changed across time (Hoek, 2016; Pike, Hoek, \& Dunne, 2014; Smink, van Hoeken, \& Hoek, 2012). Changes in ED-related concepts across time is a normal phenomenon (Theander, 2004), and therefore, it is also understandable why certain concepts are described in various ways that make it difficult to detect patterns of change. However, a study focusing on possible changes in clinical characteristics in ED patients over a period of 20 years is missing.

This retrospective study aims at detecting possible trends and/or changes in severity of ED characteristics of patients admitted for an inpatient treatment over a 
period of 20 years. Different questionnaires were administered evaluating various characteristics of eating-related pathology on a global level rather than on an individual level at three time points (1990, 2000, and 2010). All ED patients were hospitalized at the inpatient unit of the University Psychiatric Centre campus Kortenberg in Belgium.

\section{2 | METHODS}

\subsection{Participants and data collection}

The data were collected from 1,650 anonymized patient files that have been systematically collected in the time span of 25 years from 1990 to 2015 at the inpatient unit for EDs of the University Psychiatric Centre campus Kortenberg. From the total sample, three cross-sectional samples were drawn consisting of 100 consecutive female patients files admitted at the inpatient unit respectively from the first of January 1990, 2000, and 2010. All the included patients fulfilled the diagnostic criteria of either AN or BN following DSM-III (APA, 1980; for patients included from 1990) or following DSM-IV (APA, 1994; for patients included from 2000 and 2010). The diagnosis was made by the same experienced psychiatrist. The retrospective study was approved by the ethical committee of the KU Leuven (mp10237; 13.01.2016).

\section{2 | Measures}

The inpatient files comprise information-gathered by a semistructured interview-about patient specific aspects (i.e., age, weight, height, and marital status) as well as the scores from different international well-accepted questionnaires. All questionnaires show a good to excellent reliability and validity. Information was collected at admission (during the first 2 weeks) to the inpatient unit.

The Body Attitude Test (BAT; Probst, Vandereycken, Coppenolle, \& Vanderlinden, 1995; Probst, Pieters, \& Vanderlinden, 2008) is a questionnaire (20 items) developed for female patients suffering from EDs. It measures four aspects of body experience: negative appreciation of body size, lack of familiarity with one's own body, general body satisfaction, and a rest factor.

The Eating Disorder Inventory (EDI-1; Garner, Olmstead, \& Polivy, 1983) is a multidimensional self-report instrument, which aims to assess psychological characteristics (attitudes and behaviours) common in AN and BN (Garner et al., 1983). It consists of 64 items, which are divided across eight subscales: Drive for Thinness, Bulimia, Body Dissatisfaction, Ineffectiveness, Perfectionism, Interpersonal Distrust, Interoceptive Awareness, and Maturity Fears. The first three subscales evaluate symptoms related to eating and body shape, and the remaining subscales are more related to psychological aspects seen in patients with EDs (Garner et al., 1983).

The Beck Depression Inventory (Beck, Steer, \& Garbin, 1988; Beck, Ward, Mendelson, Mock, \& Erbaugh, 1961) consists of 21 items used to assess the severity of depression and changes in depression over the course of treatment, whereas its focus lies in subjective experiences of depression.

The Symptom Checklist (Derogatis, Lipman, Rickels, Uhlenhutz, \& Covi, 1974) measures a wide array of psychological symptoms and general distress. Along with a global measure for psycho-neuroticism, there are eight subscales: anxiety, agoraphobia, depression, somatization, insufficiency, sensitivity, hostility, and sleeplessness.

Three other clinical characteristics commonly observed in research related to various aspects of EDs were also included, namely, the BMI, duration of illness, and age at admission. Body weight-related measurements are presented in any kind of studies dealing with EDs. Weight (or weight-dependent tool BMI) is one of the aspects included in the diagnostic criteria in ICD-10 (World Health Organization [WHO], 1992), in various editions of DSMs (APA, 1980, 1994, 2013) as well as in research articles related to illness severity (Bravender et al., 1999; Harrington, Jimerson, Haxton, \& Jimerson, 2015; Peebles, Hardy, Wilson, \& Lock, 2010).

Duration of illness is an aspect measuring illness severity as it has been related to the length of hospital stays (Lievers et al., 2008) and reported to be a predictor of mortality (Franko et al., 2013). Even though age at onset of the illness is more commonly used in studying EDs (Pike, 1998), the data were not available for this study and age at admission was added as one of the variables.

\section{3 | Statistical analysis}

Statistical analysis was conducted with Statistica software (version 13.1). Descriptive data analysis presents means and standard deviations of all the outcome variables. In order to analyse the change across time, analysis of variance was used (significance level at $p<.05$ ) followed by post hoc test (Tukey's HSD or Unequal N HSD).

\section{3 | RESULTS}

The results of the total sample $(N=300)$ for the different outcome measures are outlined in Table 1. Analysis of variance showed no changes in BAT scores nor EDI scores between the three time points, except for a 
TABLE 1 Comparison of clinical and psychological characteristics between three cohorts of 100 patients with eating disorders starting from the January 1, 1990, 2000, and 2010

\begin{tabular}{|c|c|c|c|c|}
\hline & $\begin{array}{l}1990 \\
\text { Mean (SD) }\end{array}$ & $\begin{array}{l}2000 \\
\text { Mean (SD) }\end{array}$ & $\begin{array}{l}2010 \\
\text { Mean (SD) }\end{array}$ & $p^{\mathbf{a}}$ \\
\hline Ratio AN/BN $(N)$ & $69 / 31$ & $67 / 33$ & $63 / 37$ & \\
\hline $\operatorname{BMI}\left(\mathrm{kg} / \mathrm{m}^{2}\right)$ & $16.9(4.0)$ & $16.8(4.3)$ & $17.5(4.3)$ & ns \\
\hline Duration of illness (years) & $6.1(4.5)$ & $4.0(4.5)$ & $5.0(5.2)$ & $<.01^{\mathrm{b}}$ \\
\hline Anxiety & $27.3(10.2)$ & $25.7(9.6)$ & $24.6(8.8)$ & ns \\
\hline Agoraphobia & $13.7(6.0)$ & $13.6(6.0)$ & $13.1(5.6)$ & ns \\
\hline Depression & $51.5(15.9)$ & $51.8(15.6)$ & $50.9(14.8)$ & ns \\
\hline Somatization & $28.3(10.7)$ & $27.3(10.3)$ & $28.4(9.3)$ & ns \\
\hline Hostility & $12.3(5.4)$ & $12.3(4.4)$ & $12.1(4.5)$ & ns \\
\hline Sleep & $8.3(3.6)$ & $9.1(4.3)$ & $9.7(3.8)$ & ns \\
\hline Beck Depression Inventory & $25.2(11.6)$ & $31.3(13.8)$ & $32.6(11.5)$ & $.05^{\mathrm{bc}}$ \\
\hline Body Attitude Test & $53.4(21.3)$ & $57.3(22.2)$ & $60.1(18.0)$ & ns \\
\hline BAT factor 1 & $16.4(10.3)$ & $18.8(10.2)$ & $19.0(9.3)$ & ns \\
\hline BAT factor 2 & $17.9(8.3)$ & $18.3(8.2)$ & $20.1(7.0)$ & ns \\
\hline BAT factor 3 & $12.9(5.1)$ & $13.5(4.8)$ & $13.7(4.3)$ & ns \\
\hline BAT rest factor & $6.26(2.4)$ & $6.75(2.5)$ & $7.6(1.8)$ & $<.001^{\mathrm{cd}}$ \\
\hline Perfectionism & $7.3(4.1)$ & $6.6(4.8)$ & $7.6(4.5)$ & ns \\
\hline Interpersonal Distrust & $6.7(3.8)$ & $6.5(4.6)$ & $6.4(4.2)$ & ns \\
\hline Interceptive awareness & $10.2(6.6)$ & $11.3(6.8)$ & $11.0(6.7)$ & ns \\
\hline Maturity Fears & $7.5(5.6)$ & $6.7(5.5)$ & $8.5(6.3)$ & ns \\
\hline
\end{tabular}

Note. $S D=$ standard deviation; BAT 1 = negative appreciation of body size; BAT 2 = lack of familiarity of one's own body; BAT $3=$ general body dissatisfaction; EDI $=$ eating disorders inventory.

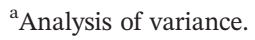

bost hoc: 1990 versus 2000 .

cpost hoc: 1990 versus 2010.

d post hoc: 2000 versus 2010.

duration of illness, age at admission, depression and BAT (rest factor). Post hoc Tukey's HSD test revealed that depression was lower in the cohort of 1990 versus 2000 and 2010; the BAT rest factor was higher in 2010 versus 1990 and 2000.

The age range of EDs patients was 13.6-40 years in $1990,13.3-46.1$ years in 2000, and 10-56 years in 2010.
The BMI ranged between $9.7-34.1 \mathrm{~kg} / \mathrm{m}^{2}$ in 1990,10 $37.4 \mathrm{~kg} / \mathrm{m}^{2}$ in 2000 , and $10.7-42.0 \mathrm{~kg} / \mathrm{m}^{2}$ in 2010 ; and the duration of illness ranged between 0.5-20 years among patients from 1990, 0.5-22 years among patients from 2000, and 0.4-22 years among patients from 2010.

Subgroup analyses for AN and BN patients separately revealed results comparable with the whole sample. 


\section{4 | DISCUSSION}

To the best of our knowledge, the current study is the first one to focus on the changes across time in a selected sample of severity measures relevant for analysing patients with EDs admitted in an inpatient treatment.

The strengths of the study include the fact that this is the first trend-study trying to analyse change in severity in ED symptoms across time and in a rather large patient sample. Additionally, a broad range of reliable and well-validated questionnaires and measurements were administered to enable a multidimensional insight into the psychological characteristics, relevant in determining the ED severity.

However, some limitations of this study should be taken into consideration. The data collection was done within an inpatient treatment setting and during the time period when an official severity index of EDs-now recently proposed by the APA (2013) — did not exist (Grilo, Ivezaj, \& White, 2015). Although three quarters of patients with EDs are diagnosed as ED no other specified (EDNOS; Le Grange, Swanson, Crow, \& Merikangas, 2012), patients with an EDNOS diagnosis were not included in the study because of the heterogeneity of the symptoms. The study was limited to patients with anorexia and BN. Hence, our study sample may be not fully representative for the ED population.

Notwithstanding these shortcomings and although only little changes in patient characteristics during a time interval of 20 years were detected at admission in the inpatient unit, some findings are interesting and deserve more attention and reflection. It could be that the diagnostic changes in the DSM across time are due to better understanding of the illness rather than changes of the clinical features. The ratio between $\mathrm{AN}$ and $\mathrm{BN}$ patients did not change during the time span of 20 years, since among all the samples approximately $1 / 3$ of patients were diagnosed with $\mathrm{BN}$ and the rest $2 / 3$ with AN. From an epidemiologic point of view, this is also an important finding. From one point of view, this is a rather unexpected finding and not in concordance with the general prevalence rates, as $\mathrm{BN}$ is commonly more prevalent than AN (APA, 1994, 2013). However, this may also reflect the fact that actual guidelines promote outpatient treatment in the case of $\mathrm{BN}$, and hence, fewer bulimic patients are referred to an inpatient unit. This appeared to be already happening more the 20 years ago. Another interesting observation is that the age range seemed to expand across the years, which reflects the changing nature of EDs and is in concordance to previous suggestions that EDs might be present among a large variety of individuals with a diverse demographical background and age (Mitchison, Hay, Slewa-Younan, \& Mond, 2014; Pike et al., 2014).
Additionally, also the range of BMI increased across the three time points, whereby it should be emphasized that especially the upper limit of BMI has increased. This finding may reflect both the heterogeneous presentation of EDs and the growing problem of overweight/obesity in general (WHO, 2016).

Only the BAT rest factor showed a significant change among all the groups (ED, AN, and BN), but it should be kept in mind that the rest factor includes only two items (Item 15: My bodily appearance is very important to me; Item 20: I am observing my appearance in the mirror). This finding seems to suggest an increase and a greater obsession with bodily appearance over the years.

The Beck Depression Inventory scores showed that patients with EDs exhibit an increase in scores over each decade; however, the increase in reported depressive symptoms is only significant between 1990 and 20002010. Despite that, this finding shows that in later cohorts (2000 and 2010), the patients report a more severe state of depression, whereas in 1990, the majority revealed a moderate depression score (Beck et al., 1988). The data further show that EDI increased; however, the increase was not significant. The results indicate that clinicians must systematically screen for the presence of depressive symptoms and try to find out the origin of these depressive symptoms. Vanderlinden and Palmisano (2018) hypothesized that in patient with EDs, an increase in depression may be related to an increase in "emotional neglect."

To conclude, to the best of our knowledge, this is the first study to compare ED characteristics across a 20-year period. Overall, not many changes have been noticed over the years except for depression and an obsession with bodily appearance, which both seem to increase in both $\mathrm{AN}$ and $\mathrm{BN}$ patients in the last decennia. Moreover, it could be that 20 years are not enough to study changes of clinical features.

\section{ORCID}

Michel Probst (D) http://orcid.org/0000-0002-1389-4862

\section{REFERENCES}

American Psychiatric Association (1980). Diagnostic and statistical manual of mental disorders (3rd ed., text rev ed.). Washington, DC: American Psychiatric Association.

American Psychiatric Association (1994). Diagnostic and statistical manual of mental disorders (4th ed., text rev ed.). Washington, DC: American Psychiatric Association.

American Psychiatric Association (2013). Feeding and eating disorders. In Diagnostic and statistical manual of mental disorders (5th ed.) (pp. 338-350). Washington DC: American Psychiatric Association. 
Beck, A. T., Steer, R. A., \& Garbin, M. (1988). Psychometric properties of the Beck Depression Inventory: Twenty-five years of evaluation. Clinical Psychology Review, 8, 77-100. https://doi. org/10.1016/0272-7358(88)90050-5

Beck, A. T., Ward, C. H., Mendelson, M., Mock, J., \& Erbaugh, J. (1961). An inventory for measuring depression. Archives of General Psychiatry, 4, 561-571.

Bravender, T., Robertson, L., Woods, E. R., Gordon, C. M., \& Forman, S. (1999). Is there an increased clinical severity of patients with eating disorders under managed care? Journal of Adolescent Health, 24(6), 422-426. https://doi.org/10.1016/ S1054-139X(98)00143-8

Bruch, H. (1962). Perceptual and conceptual disturbances in anorexia nervosa. Psychosomatic Medicine, 24, 187-194.

Derogatis, L. R., Lipman, R. S., Rickels, K., Uhlenhutz, E. H., \& Covi, L. (1974). The Hopkins Symptom Check List. Pharmacopsychotherapy, 17, 79-110.

Franko, D. L., Keshaviah, A., Eddy, K. T., Krishna, M., Davis, M. C., Keel, P. K., \& Herzog, D. B. (2013). A longitudinal investigation of mortality in anorexia nervosa and bulimia nervosa. The American Journal of Psychiatry, 170(8), 917-925. https://doi. org/10.1176/appi.ajp.2013.12070868

Garner, D. M., Olmstead, M. P., \& Polivy, J. (1983). Development and validation of a multidimensional eating disorder inventory for anorexia nervosa and bulimia. International Journal of Eating Disorders, 2(2), 15-34. https://doi.org/10.1002/1098108X(198321)2:2\%3C15::AID-EAT2260020203\%3E3.0.CO;2-6

Grilo, C. M., Ivezaj, V., \& White, M. A. (2015). Evaluation of the DSM-5 severity indicator for bulimia nervosa. Behaviour Research and Therapy, 67, 41-44. https://doi.org/10.1016/j. brat.2015.02.002

Harrington, B. C., Jimerson, M., Haxton, C., \& Jimerson, D. C. (2015). Initial evaluation, diagnosis, and treatment of anorexia nervosa and bulimia nervosa. American Family Physician, 91(1), 46-52.

Haynos, A. F., Roberto, C. A., \& Attia, E. (2015). Examining the associations between emotion regulation difficulties, anxiety, and eating disorder severity among inpatients with anorexia nervosa. Comprehensive Psychiatry, 60, 93-98. https://doi.org/ 10.1016/j.comppsych.2015.03.004

Hoek, H. W. (2016). Review of the worldwide epidemiology of eating disorders. Current Opinion in Psychiatry, 29(6), 336-339. https://doi.org/10.1097/YCO.0000000000000282

Le Grange, D., Swanson, S. A., Crow, S. J., \& Merikangas, K. R. (2012). Eating disorder not otherwise specified presentation in the US population. International Journal of Eating Disorders, 45(5), 711-718. https://doi.org/10.1002/eat.22006

Lievers, L. S., Curt, F., Wallier, J., Perdereau, F., Rein, Z., Jeammet, P., \& Godart, N. (2008). Predictive factors of length of inpatient treatment in anorexia nervosa. European Child and Adolescent Psychiatry, 18(2), 75-84. https://doi.org/10.1007/s00787-0080706-8

Mitchison, D., Hay, P., Slewa-Younan, S., \& Mond, J. (2014). The changing demographic profile of eating disorder behaviors in the community. BMC Public Health, 14, 943. https://doi.org/ 10.1186/1471-2458-14-943
Peebles, R., Hardy, K. K., Wilson, J. L., \& Lock, J. D. (2010). Are diagnostic criteria for eating disorders markers of medical severity? Pediatrics, 125(5), e1193-e1201. https://doi.org/ 10.1542/peds.2008-1777

Pike, K. M. (1998). Long-term course of anorexia nervosa: response, relapse, remission, and recovery. Clinical Psychology Review, 18(4), 447-475. https://doi.org/10.1016/S0272-7358(98)00014-2

Pike, K. M., Hoek, H. W., \& Dunne, P. E. (2014). Cultural trends and eating disorders. Current Opinion in Psychiatry, 27(6), 436-442. https://doi.org/10.1097/YCO.0000000000000100

Probst, M., Pieters, G., \& Vanderlinden, J. (2008). Evaluation of body experience questionnaires in eating disorders in female patients $(\mathrm{AN} / \mathrm{BN})$ and nonclinical participants. International Journal of Eating Disorders, 41(7), 657-665. https://doi.org/ 10.1002/eat.20531

Probst, M., Vandereycken, W., Coppenolle, H., \& Vanderlinden, J. (1995). The Body Attitude Test for patients with an eating disorder: Psychometric characteristics of a new questionnaire. Eating Disorders, 3(2), 133-144. https://doi.org/10.1080/10640269508 249156

Russell, G. (1979). Bulimia nervosa: An ominous variant of anorexia nervosa. Psychological Medicine, 9, 429-448.

Smink, F. R. E., van Hoeken, D., \& Hoek, H. W. (2012). Epidemiology of eating disorders: Incidence, prevalence and mortality rates. Current Psychiatry Reports, 14(4), 406-414. https://doi. org/10.1007/s11920-012-0282-y

Spindler, A., \& Milos, G. (2007). Links between eating disorder symptom severity and psychiatric comorbidity. Eating Behaviors, 8(3), 364-373. https://doi.org/10.1016/j.eatbeh.2006.11.012

Theander, S. S. (2004). Trends in the literature on eating disorders over 36 years (1965-2000): Terminology, interpretation and treatment. European Eating Disorders Review, 12, 4-17. https:// doi.org/10.1002/erv.559

Treasure, J., Claudino, A. M., \& Zucker, N. (2010). Eating disorders. Lancet, 375, 583-593. https://doi.org/10.1016/S0140-6736(09)6 1748-7

Vanderlinden, J., \& Palmisano, G. (2018). Trauma and the eating disorders: A literature review (chapter 2). In A. Seubert, \& P. Virdi (Eds.), Trauma-informed approaches to eating disorders. NY: Springer Publications.

World Health Organization. (2016, June). Obesity and overweight. Fact sheet by World Health Organisation (WHO). Retrieved from: http://www.who.int/mediacentre/factsheets/fs311/en/ accessed 12.04.2017

World Health Organization. (1992). The ICD-10 classification of mental and behavioural disorders: clinical descriptions and diagnostic guidelines. Retrieved from: http://www.who.int/classifications/icd/en/bluebook.pdf

How to cite this article: Probst M, Kürsa K, Van Damme T, Diedens J, Vanderlinden J. Changes in eating disorder characteristics over the years. Eur Eat Disorders Rev. 2018;1-5. https://doi.org/ 10.1002/erv.2603 